\title{
The Effect of Age on Short-Term Outcomes After Abdominal Surgery for Pelvic Organ Prolapse
}

\author{
Holly E. Richter, PhD, MD, ${ }^{*}$ Patricia S. Goode, MD, ${ }^{\dagger \neq}$ Kim Kenton, MD, MS, ${ }^{\mathcal{S}}$ Morton B. Brown, \\ PhD, "Kathryn L. Burgio, PhD, ${ }^{\dagger}$ Karl Kreder, MD, "Pamela Moalli, MD, PhD, " E. James Wright, \\ $M D,{ }^{* *}$ and Anne M. Weber, MD, MS, ${ }^{\dagger \dagger}$ for the Pelvic Floor Disorders Network
}

OBJECTIVES: To compare perioperative morbidity and 1-year outcomes of older and younger women undergoing surgery for pelvic organ prolapse (POP).

DESIGN: Prospective ancillary analysis.

SETTING: Academic medical centers in National Institutes of Health, National Institute of Child Health and Human Development Colpopexy and Urinary Reduction Study.

PARTICIPANTS: Women with POP and no symptoms of stress incontinence.

INTERVENTION: Abdominal sacrocolpopexy with randomization to receive Burch colposuspension for treatment of possible occult incontinence or not.

MEASUREMENTS: Perioperative complications and Pelvic Organ Prolapse Quantification and quality-of-life (QOL) questionnaires (Pelvic Floor Distress Inventory, Pelvic Floor Impact Questionnaire, and Medical Outcomes Study Short-Form Health Survey (SF-36) preoperatively, immediately postoperatively, and 6 weeks and 3 and 12 months postoperatively).

RESULTS: Three hundred twenty-two women aged 31 to $82(21 \%$ aged $\geq 70), 93 \%$ white. Older women had higher baseline comorbidity $(P<.001)$ and more severe POP $(P=.003)$. Controlling for prolapse stage and whether

From the * Department of Obstetrics and Gynecology and ${ }^{\ddagger}$ Division of Gerontology and Geriatrics and Palliative Medicine, University of Alabama at Birmingham, Birmingham, Alabama; ${ }^{\dagger}$ Birmingham/Atlanta Geriatric Research, Education and Clinical Center, Department of Veterans Affairs Medical Center, Birmingham, Alabama; ${ }^{\$}$ Department of Obstetrics and Gynecology, Loyola University, Maywood, Illinois; "Department of Biostatistics, University of Michigan, Ann Arbor Michigan; "Department of

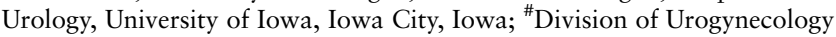
and Pelvic Reconstructive Surgery, University of Pittsburgh, Pittsburgh,

Pennsylvania; ${ }^{* *}$ Department of Urology, Johns Hopkins School of Medicine, Baltimore, Maryland; and ${ }^{\dagger \dagger}$ National Institutes of Child Health and Human Development, Bethesda, Maryland.

Presented as Presidential Award Poster at American Geriatrics Society Annual Meeting, May 4-6, 2006, Chicago, Illinois.

Address correspondence to Holly E. Richter, PhD, MD, Women's Pelvic Medicine and Reconstructive Surgery, University of Alabama at Birmingham, 620 20th Street South, NHB 219, Birmingham, AL 35233.

E-mail: hrichter@uab.edu

DOI: $10.1111 / j .1532-5415.2007 .01178 . x$
Burch was performed, there were no age differences in complication rates. Older women had longer hospital stays $(3.1 \pm 1.0$ vs $2.7 \pm 1.5$ days, $P=.02)$ and higher prevalence of incontinence at 6 weeks $(54.7 \%$ vs $37.2 \%, P=.005)$. At 3 and 12 months, there were no differences in self-reported incontinence, stress testing for incontinence, or prolapse stage. Improvements from baseline were significant on all QOL measures but with no age differences.

CONCLUSION: Outcomes of prolapse surgery were comparable between older and younger women except that older women had slightly longer hospital stays. J Am Geriatr Soc 55:857-863, 2007.

Key words: surgery; pelvic organ prolapse; older women; outcomes; quality of life; length of stay

$P$ elvic floor disorders, including urinary incontinence, fecal incontinence, and pelvic organ prolapse (POP), increase in prevalence with age. ${ }^{1}$ As a result of increase in overall life expectancy, it is estimated that the number of women aged 85 and older will double to more than 6 million by $2030 .^{2}$ It is estimated that these demographic changes will cause the demand for pelvic floor medical services to rise at twice the rate of growth of the total population over the next 3 decades. Surgery, one of the most effective treatment modalities for POP, can be associated with significant complications, especially in older people. Before patients can be adequately counseled about surgical therapy, accurate age-specific data for efficacy and surgical morbidity are needed.

Despite the pressing need for surgical outcomes data in older patients, there is a relative paucity of such information in the literature. ${ }^{3}$ In fact, older patients are often specifically excluded from clinical trials. One study reported that one-third of original research papers in major medical journals excluded elderly patients without justification. ${ }^{4}$ The data that exist regarding surgical outcomes in older patients are somewhat mixed.

One study using data from the Nationwide Inpatient Sample of 264,340 patients reported that older women had 
a higher risk of morbidity and mortality after urogynecological surgery. ${ }^{5}$ Similarly, in a retrospective review of 226 women undergoing surgery for incontinence at a large referral center, women aged 70 and older had a higher risk of complications than those younger than 70.6 Conversely, a retrospective chart review of 267 patients aged 75 and older who underwent urogynecological surgery found a low overall perioperative morbidity rate, although preexisting cardiovascular disease increased the incidence of perioperative complications. ${ }^{7}$ A study of 128 patients aged 80 and older who had surgery for POP concluded that the operative correction of POP had acceptable morbidity and a high satisfaction rate. ${ }^{8}$

The purpose of this article is to compare perioperative morbidity and surgical and quality of life (QOL) outcomes at 6 weeks and 3 and 12 months in women aged 70 and older with those younger than 70 undergoing abdominal surgery for POP.

\section{METHODS}

This was a prospective ancillary analysis of the Colpopexy and Urinary Reduction (CARE) Study. The study was performed through the Pelvic Floor Disorders Network, a cooperative network sponsored by the National Institute of Child Health and Human Development. The methods and primary outcome of CARE have been reported previously. ${ }^{9,10}$ Briefly, women with Stage II, III, or IV prolapse ${ }^{11}$ undergoing an abdominal sacrocolpopexy with no subjective evidence of urinary stress incontinence and sufficient urethral mobility for a Burch urethropexy were invited to participate in the study. The abdominal sacrocolpopexy was performed through a laparotomy incision, a laparoscopic approach was not allowed in this protocol. All women provided written informed consent to participate, and eligible women were enrolled between March 2002 and February 2005.

On the day of surgery, study participants undergoing a sacrocolpopexy were randomized in the operating room to have or not have a concomitant Burch colposuspension procedure. Study participants and the research staff who performed the follow-up assessments were blinded to the treatment assignments for a minimum of 3 months and up to 3 years. For the outcome variables analyzed in this paper, the CARE population was dichotomized into women aged 70 and older and those younger than 70 .

Objective assessments of POP and incontinence and symptom-specific and general QOL questionnaires were collected preoperatively and postoperatively at 6 weeks and 3 and 12 months. Objective assessment of prolapse was performed using the Pelvic Organ Prolapse Quantification Examination (POP-Q). ${ }^{11}$ At baseline, a research nurse assessed preoperative urodynamics according to a study protocol with prolapse unreduced and then with prolapse reduced. Postoperatively, stress incontinence was measured objectively at 3 months using a standardized stress test at $300 \mathrm{ml}$ or maximum capacity (whichever was less), in the sitting and then the standing position, using Valsalva or cough as the stress maneuver.

Women completed QOL questionnaires by telephone survey conducted by the Quality of Life Interviewing Center at the University of Michigan. Condition-specific QOL instruments included the Pelvic Floor Distress Inventory (PFDI) and Pelvic Floor Impact Questionnaire (PFIQ) for the assessment of pelvic symptoms and their effect on QOL. ${ }^{12}$ The three subscales of the PFDI were analyzed separately: the Urinary Distress Inventory (28 items), the Colorectal-Anal Distress Inventory (17 items), and the Pelvic Organ Prolapse Distress Inventory (16 items). The three subscales of the PFIQ were also analyzed separately: the Incontinence Impact Questionnaire (31 items), the Colorectal-Anal Impact Questionnaire (31 items), and the Pelvic Organ Prolapse Impact Questionnaire (31 items).

General QOL was assessed using the 36-item Medical Outcomes Study Short-Form Health Survey (SF-36). ${ }^{13}$ The SF-36 has two summary indexes, the Mental Component Summary (MCS) and the Physical Component Summary (PCS), which are derived from the weighted averages of the individual domain scores. ${ }^{14}$ Sexual function was measured using the Pelvic Organ Prolapse/Urinary Incontinence Sexual Function Questionnaire. ${ }^{15}$ For all QOL measures, the median value of the subscale at baseline was calculated, as well as the mean change from baseline at each follow-up time point.

A comorbidity index, the Cumulative Illness Rating Scale (CIRS) ${ }^{16}$ was used to quantitate the burden of chronic illness. Serious adverse events, defined as untoward medical occurrences that were life threatening or fatal or required prolonged hospitalization or readmission for the index surgery, any condition that resulted in persistent or clinically significant disability, or any other important medical condition that occurred in the immediate intra- or postoperative and short-term (6 weeks, 3 and 12 months) postoperative periods were recorded. A committee of three investigators reviewed serious adverse events and used consensus to group them by the affected organ system or as febrile illnesses, wound complications, or the need for a blood transfusion.

Demographic data collected at baseline included age, race, marital status, level of education, employment status, and insurance type. Baseline variables collected from past medical history included mode of delivery, use of hormone therapy, smoking status, previous treatments for urinary incontinence and POP, previous hysterectomy, and medical comorbidities (diabetes mellitus, coronary-vascular disease, and lung disease).

Data collected intraoperatively included whether a Burch procedure was performed and the length of the surgery. Immediate postoperative data collection included the length of hospital stay, blood transfusion (including intraoperative), wound complications, and febrile complications. In addition, any organ damage or cardiovascular, pulmonary, gastrointestinal, or neurological serious adverse events were noted. The need for an indwelling urinary catheter or performance of clean intermittent selfcatheterization and the number of days required for each were included in the postoperative outcomes. Leakage of urine postoperatively was defined as answering "yes" to any of the three questions on the PFDI stress incontinence subscale or stress incontinence observed on the bladder fill stress test. Also, a general self-report question ascertaining any urine leakage was asked at 6 weeks and 3 and 12 months postoperatively. 


\section{Analysis}

At baseline, the two groups were compared using a twosample $t$ test for continuous measures or the Fisher exact test or chi-square test for discrete variables. For outcome variables, a general linear model was fit to the continuous measures; age ( $\geq 70$ vs $<70$ ) was included as an indicator variable, and the models included as covariates the baseline stage of POP and whether a Burch procedure was performed (i.e., all $P$-values for outcome measures were adjusted for POP stage and performance of Burch procedure). Because PFDI and PFIQ scores were not normally distributed, analyses were performed after a square root transformation. When the outcome measure was discrete (dichotomous), the Mantel-Haenszel statistic (a chi-square statistic) was computed after adjustment for POP and performance of the Burch procedure.

Although planned prospectively, this comparison was not a primary aim of the CARE study. The following calculations of power indicate the underlying differences between groups that can be tested with $80 \%$ power; they were not used to determine the sample size. With the sample size available for this analysis (255 women $<70 ; 67$ women $\geq 70$ ), there was $80 \%$ power to differentiate between proportions of 0.05 and 0.17 , between 0.10 and 0.25 , between 0.20 and 0.38 , and between 0.40 and 0.60 when testing at a $5 \%$ level of significance. Also, when the dependent measure is continuous, there is $80 \%$ power to identify a change of 0.4 standard deviations (an effect size of 0.4 ) when comparing the two groups at a $5 \%$ level of significance. Results are presented as mean \pm standard deviation or $\mathrm{n}(\%)$, and $P$-values without a correction for the number of tests performed.

\section{RESULTS}

Three hundred twenty-two women, ranging in age from 31 to 82 , were enrolled. Twenty-one percent of participants were aged 70 and older, and $93 \%$ were white. Table 1 displays baseline characteristics for both groups. More older than younger women had had prior hysterectomy and previous prolapse surgery. Older women had higher baseline comorbidity based on CIRS score and were more likely to

\begin{tabular}{|c|c|c|c|}
\hline Characteristic & $\begin{array}{c}\text { Aged }<70 \\
n=255\end{array}$ & $\begin{array}{c}\text { Aged } \geq 70 \\
n=67\end{array}$ & $P$-value* \\
\hline \multicolumn{4}{|l|}{ Age } \\
\hline Mean \pm SD & $57.9 \pm 8.5$ & $74.5 \pm 3.1$ & \\
\hline Median (range) & $59(31-69)$ & $74(70-82)$ & \\
\hline \multicolumn{4}{|l|}{ Race, $n(\%)$} \\
\hline White/Caucasian & $235(92.2)$ & $64(95.5)$ & .82 \\
\hline Black/African-American & $15(5.9)$ & $2(3.0)$ & \\
\hline Vaginal deliveries & & & $<.001$ \\
\hline Mean \pm SD & $2.8 \pm 1.4$ & $3.6 \pm 1.4$ & \\
\hline Median (range) & $3(0-11)$ & $3(1-7)$ & \\
\hline Current smoker, n (\%) & $20(7.9)$ & $3(4.5)$ & .43 \\
\hline Estrogen replacement therapy, $\mathrm{n}(\%)$ & $99(39.0)$ & 29 (43.3) & .58 \\
\hline Previous medication or drug treatment for incontinence, $\mathrm{n}(\%)$ & $14(5.5)$ & $4(6.0)$ & 1.00 \\
\hline $\begin{array}{l}\text { Previous bladder training, pelvic muscle exercises, electrical stimulation, } \\
\text { or biofeedback for urinary incontinence, } n(\%)\end{array}$ & $19(7.5)$ & $9(13.4)$ & .14 \\
\hline Previous pessary treatment for incontinence, $\mathrm{n}(\%)$ & $13(5.1)$ & $10(14.9)$ & .01 \\
\hline Previous incontinence surgery, $\mathrm{n}(\%)$ & $16(6.3)$ & $6(9.0)$ & .42 \\
\hline Previous prolapse surgery, $\mathrm{n}(\%)$ & $93(36.6)$ & $33(49.3)$ & .07 \\
\hline Hysterectomy, $\mathrm{n}(\%)$ & $167(80.3)$ & $59(93.7)$ & .01 \\
\hline Diabetes mellitus, $n(\%)$ & $12(4.7)$ & $4(6.0)$ & .75 \\
\hline Cumulative IIIness Rating Scale score, mean \pm SD & $3.7 \pm 3.0$ & $5.1 \pm 3.1$ & $<.001$ \\
\hline Body mass index, median (range) & $26(20-49)$ & $26(19-39)$ & .27 \\
\hline Pelvic Organ Prolapse Quantification Examination Stage & & & .003 \\
\hline Mean \pm SD & $3.0 \pm 0.6$ & $3.2 \pm 0.6$ & \\
\hline Median (range) & $3(2-4)$ & $3(2-4)$ & \\
\hline \multicolumn{4}{|l|}{ Frequency Stage, n (\%) } \\
\hline II & $40(15.7)$ & $4(6.0)$ & \\
\hline III & $174(68.2)$ & $43(64.2)$ & \\
\hline IV & $41(16.1)$ & $20(29.9)$ & \\
\hline \multicolumn{4}{|l|}{ Medical Outcomes Study Short-Form Health Survey, median (range) } \\
\hline Physical Component Summary score & $47(11-64)$ & $45(23-61)$ & .43 \\
\hline Mental Component Summary score & $54(18-69)$ & $54(20-63)$ & .94 \\
\hline
\end{tabular}

${ }^{*} P$-value was computed using two-sample $t$ test (when continuous), Fisher exact test (when dichotomous), or chi-square test. $\mathrm{SD}=$ standard deviation . 
Table 2. Perioperative Complications and Utilization

\begin{tabular}{|c|c|c|c|}
\hline Characteristic & $\begin{array}{c}\text { Aged }<70 \\
\mathrm{n}=255\end{array}$ & $\begin{array}{c}\text { Aged } \geq 70 \\
n=67\end{array}$ & $P$-value* \\
\hline \multicolumn{4}{|l|}{ Wound complications, n (\%) } \\
\hline Immediate & $3(1.2)$ & $2(3.1)$ & .14 \\
\hline 6 weeks & $25(10.1)$ & $6(9.4)$ & .93 \\
\hline \multicolumn{4}{|l|}{ Febrile/dermatologic complications, n (\%) } \\
\hline Immediate & $27(10.7)$ & $8(12.3)$ & .58 \\
\hline 6 weeks & $28(11.3)$ & $9(14.3)$ & .27 \\
\hline \multicolumn{4}{|l|}{ Cardiovascular complications, $\mathrm{n}(\%)$} \\
\hline Immediate & $12(4.8)$ & $4(6.1)$ & .82 \\
\hline 6 weeks & $3(1.2)$ & $1(1.6)$ & .79 \\
\hline \multicolumn{4}{|l|}{ Pulmonary complications, n (\%) } \\
\hline Immediate & $23(9.1)$ & $4(6.1)$ & .63 \\
\hline 6 weeks & $3(1.2)$ & $1(1.6)$ & .78 \\
\hline \multicolumn{4}{|l|}{ Gastrointestinal complications, n (\%) } \\
\hline Immediate & $48(19.0)$ & $13(19.7)$ & 1.00 \\
\hline 6 weeks & $33(13.2)$ & $11(17.2)$ & .37 \\
\hline \multicolumn{4}{|l|}{ Neurologic complications, $\mathrm{n}(\%)$} \\
\hline Immediate & $2(0.8)$ & 0 & .45 \\
\hline 6 weeks & $7(2.8)$ & 0 & .20 \\
\hline Catheter at discharge, $\mathrm{n}(\%)$ & 75 (29.4) & $13(19.4)$ & .11 \\
\hline Requires catheterization at 6 weeks, $\mathrm{n}(\%)$ & $3(1.2)$ & 0 & .30 \\
\hline Any leakage of urine according to self-report at 6 weeks, $n(\%)$ & $93(37.2)$ & $35(54.7)$ & .005 \\
\hline Length of stay, days, mean \pm standard deviation & $2.7 \pm 1.0$ & $3.1 \pm 1.5$ & .02 \\
\hline \multicolumn{4}{|l|}{ Rehospitalization, n (\%) } \\
\hline To Week 6 & $15(5.9)$ & $5(7.8)$ & .50 \\
\hline 6-12 Weeks & $3(1.2)$ & $3(4.5)$ & .06 \\
\hline
\end{tabular}

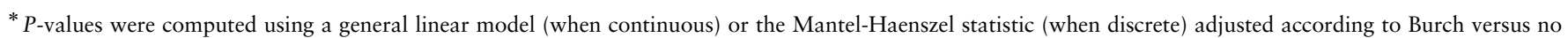
Burch and baseline Pelvic Organ Prolapse Quantification Examination.

have Stage III or IV POP. There were no differences between cohorts in baseline urodynamics, subscales of the PFDI or PFIQ, or SF-36 MCS or PCS scores.

Fifty-five percent of older women and $47 \%$ of younger women were randomized to Burch along with sacrocolpopexy $(P=.27)$. Table 2 shows common perioperative complications and utilization data for each group. There were no deaths up to 1 year and only three withdrawals from the study, all in women younger than 70 . There were no differences by age group in any perioperative complication rates. Length of hospital stay was longer in the older women ( $3.1 \pm 1.0$ vs $2.7 \pm 1.5$ days, $P=.02)$. This difference remained significant after adjustment for baseline comorbidity (CIRS score) $(P=.04)$. Rehospitalization rates were virtually the same in both age groups during the first 6 weeks (older $7.5 \%$ vs younger $5.9 \% ; P=.66$ after adjusting for baseline comorbidity). Rehospitalization rates between 6 weeks and 3 months were higher in older women but not statistically significant $(4.5 \%$ vs $1.2 \%, P=.12$ after adjusting for baseline comorbidity). The most common reasons for rehospitalization were related to the surgery and included ileus and small bowel obstruction, pelvic infection, and mesh erosion. Other reasons for rehospitalization included chest pain, fever, hip fracture after fall, hypokalemia, and vitamin $\mathrm{B}_{12}$ deficiency.

At 6 weeks, more older women reported leakage of urine $(54.7 \%$ vs $37.2 \%, P=.005)$, but at 3 months (Table 3), there was no difference in self-report of urine leakage, incontinence rates by stress test, or prolapse stage.
There were significant improvements from baseline on all the QOL measures for both age groups, including symptom-specific QOL measures and improvements in the PCS and MCS scores of the SF-36, although there were no differences in the baseline to 3-month change scores between subjects aged 70 and older and those who were younger. At 12 months, there continued to be no differences between the two age groups in prolapse stage, self-report of any urine leakage, incontinence rates by stress test, or magnitude of QOL and symptom score changes from baseline (Table 4).

\section{DISCUSSION}

Aging is associated with changes that can affect surgical outcomes. These include physiological, functional, and cognitive issues. ${ }^{17,18}$ As women are living longer, it is expected that there will be an increase in surgery for pelvic floor disorders, yet little information exists regarding perioperative complications and outcomes of elective gynecological pelvic floor surgery, especially with an abdominal approach, in older and younger women. This type of information can help doctors more effectively counsel all of their patients undergoing surgery for urinary incontinence and POP. Studies assessing the morbidity and mortality from gynecological surgery in older woman reveal minimal or no increase in mortality attributable to age alone but do indicate greater morbidity related to underlying comorbidities. ${ }^{19,20}$ Fewer studies compare perioperative outcomes between groups of older and younger women. ${ }^{20,21}$ 
Table 3. Three-Month Postoperative Outcomes

\begin{tabular}{|c|c|c|c|}
\hline Characteristic & $\begin{array}{c}\text { Age }<70 \\
\mathrm{n}=247\end{array}$ & $\begin{array}{l}\text { Aged } \geq 70 \\
\quad \mathrm{n}=66\end{array}$ & $P$-value* \\
\hline POP-Q stage of prolapse (0-3), median (range) & $1(0-3)$ & $1(0-3)$ & 20 \\
\hline Leakage of any urine, $\mathrm{n}(\%)$ & $127(51.4)$ & $38(57.6)$ & .28 \\
\hline Leakage on cough stress test, $\mathrm{n}(\%)$ & $13(5.4)$ & $3(4.8)$ & .85 \\
\hline \multicolumn{4}{|l|}{ Change in Medical Outcomes Study Short-Form } \\
\hline \multicolumn{4}{|l|}{ Health Survey, mean \pm SD } \\
\hline Physical Component Summary score & $1.7 \pm 9.4$ & $0.7 \pm 7.6$ & .40 \\
\hline Mental Component Summary score & $0.7 \pm 9.7$ & $0.5 \pm 7.7$ & .72 \\
\hline \multicolumn{4}{|l|}{$\begin{array}{l}\text { Change in Pelvic Floor Distress Inventory component, } \\
\text { mean } \pm \text { SD }\end{array}$} \\
\hline Urinary Distress Inventory & $-33.1 \pm 40.8$ & $-31.6 \pm 53.5$ & 42 \\
\hline Colorectal-Anal Distress Inventory & $-33.9 \pm 64.6$ & $-41.4 \pm 58.2$ & .45 \\
\hline Pelvic Organ Prolapse Distress Inventory & $-73.5 \pm 61.3$ & $-82.7 \pm 65.4$ & .43 \\
\hline \multicolumn{4}{|l|}{$\begin{array}{l}\text { Change in Pelvic Floor Impact Questionnaire component, } \\
\text { mean } \pm \text { SD }\end{array}$} \\
\hline Urinary Incontinence Questionnaire & $-22.2 \pm 54.7$ & $-19.4 \pm 48.0$ & .46 \\
\hline Colorectal-Anal Impact Questionnaire & $-14.2 \pm 47.9$ & $-15.1 \pm 39.5$ & .90 \\
\hline Pelvic Organ Prolapse Impact Questionnaire & $-31.6 \pm 54.0$ & $-25.9 \pm 44.0$ & .43 \\
\hline $\begin{array}{l}\text { Change in Pelvic Organ Prolapse/Urinary Incontinence } \\
\text { Sexual Function Questionnaire, mean } \pm \text { SD }\end{array}$ & $3.1 \pm 6.3$ & $3.4 \pm 4.7$ & .68 \\
\hline
\end{tabular}

${ }^{*} P$-values were computed using a general linear model (when continuous) or the Mantel-Haenszel statistic (when discrete) adjusted according to Burch versus no Burch and baseline Pelvic Organ Prolapse Quantification Examination (POP-Q). $\mathrm{SD}=$ standard deviation.

Overall, short-term outcomes of abdominal surgery for significant POP were comparable between women aged 70 and older and those younger than 70. Older women had more subjective complaints of incontinence at 6 weeks but no difference at 3 and 12 months. The low prevalence of postoperative complications in both groups may reflect an inherent bias of surgeons to select patients with the likelihood of undergoing major elective surgery uneventfully, whereas the frailer women with POP may be offered nonsurgical treatments. This could be entirely appropriate, but further study of selection criteria, particularly age as a criterion, for successful pelvic surgery is needed. Despite

Table 4. Twelve-Month Postoperative Outcomes

\begin{tabular}{|c|c|c|c|}
\hline Characteristic & $\begin{array}{l}\text { Aged }<70 \\
n=223\end{array}$ & $\begin{array}{l}\text { Aged } \geq 70 \\
n=64\end{array}$ & $P$-value* \\
\hline POP-Q stage of prolapse (0-3), median (range) & $1(0-3)$ & $1(0-2)$ & .86 \\
\hline Leakage of any urine, $n(\%)$ & $107(48.2)$ & $30(46.9)$ & .94 \\
\hline Leakage on cough stress test, $\mathrm{n}(\%)$ & $7(3.3)$ & $1(1.7)$ & .55 \\
\hline \multicolumn{4}{|l|}{ Change in Medical Outcomes Study Short-Form } \\
\hline \multicolumn{4}{|l|}{ Health Survey, mean \pm SD } \\
\hline Physical Component Summary score & $3.8 \pm 8.8$ & $2.4 \pm 8.0$ & .35 \\
\hline Mental Component Summary score & $0.6 \pm 8.8$ & $1.1 \pm 7.9$ & .78 \\
\hline \multicolumn{4}{|l|}{$\begin{array}{l}\text { Change in Pelvic Floor Distress Inventory component, } \\
\text { mean } \pm \text { SD }\end{array}$} \\
\hline Urinary Distress Inventory & $-35.4 \pm 38.1$ & $-34.7 \pm 55.4$ & .43 \\
\hline Colorectal-Anal Distress Inventory & $-35.8 \pm 58.2$ & $-38.2 \pm 61.9$ & .82 \\
\hline Pelvic Organ Prolapse Distress Inventory & $-74.3 \pm 58.9$ & $-78.8 \pm 73.1$ & .82 \\
\hline \multicolumn{4}{|l|}{$\begin{array}{l}\text { Change in Pelvic Floor Impact Questionnaire component, } \\
\text { mean } \pm \text { SD }\end{array}$} \\
\hline Urinary Incontinence Questionnaire & $-28.8 \pm 47.3$ & $-25.7 \pm 49.3$ & .42 \\
\hline Colorectal-Anal Impact Questionnaire & $-18.6 \pm 44.6$ & $-12.9 \pm 41.3$ & .43 \\
\hline Pelvic Organ Prolapse Impact Questionnaire & $-36.2 \pm 55.9$ & $-23.7 \pm 41.6$ & .09 \\
\hline $\begin{array}{l}\text { Change in Pelvic Organ Prolapse/Urinary Incontinence } \\
\text { Sexual Function Questionnaire, mean } \pm \text { SD }\end{array}$ & $3.2 \pm 5.5$ & $0.6 \pm 4.3$ & .09 \\
\hline
\end{tabular}

${ }^{*} P$-values were computed using a general linear model (when continuous) or the Mantel-Haenszel statistic (when discrete) adjusted according to Burch versus no Burch and baseline Pelvic Organ Prolapse Quantification Examination (POP-Q).

$\mathrm{SD}=$ standard deviation. 
this potential for bias, a strength of this study is that more than 10 surgeons in seven academic medical centers across the United States with potentially different individualized approaches to patient care recruited patients into the study. Therefore, the selection bias in this study should be generalizable, at least for gynecologists and urologists specializing in pelvic floor surgery in academic medical centers.

Older women did have a slightly longer length of stay. Length of hospital stay for surgery can have important implications for cost of care. The older women in this study were hospitalized approximately half a day longer than the younger women. Although this longer stay may not seem clinically important, the economic significance from a hospital and insurance payer point of view may be substantial. An analysis of Medicare data examining morbidity and mortality of continence surgery in older women ${ }^{22}$ showed that, in 66,478 patients with a mean and median age of 71 (range 65-100), length of stay increased linearly with age. In this report, an analysis of comorbidities was performed to determine whether the presence of medical problems affected length of stay. The effect of the most common chronic comorbidities (hypertension, diabetes mellitus, chronic obstructive pulmonary disease, and dementia) did not significantly affect length of stay, whereas the presence of congestive heart failure slightly increased length of stay. In the current study, the age-related increase in length of stay was independent of comorbidity. Further exploration of factors associated with length of stay after surgery should include ascertaining the level of postdischarge supportive care needed at home. Such studies could lead to alternative models of transitional care that could reduce costs by shortening length of stay, such as a home health aide for a day or two after hospital discharge.

A strength of the study was use of multiple standardized outcome measures administered by trained investigators blinded to treatment group. The multisite design of the trial was another strength and increases overall generalizability, although the trial occurred primarily at academic tertiary referral centers, which limits generalizability. Another limitation of the study was that, despite a large sample size $(\mathrm{N}=322)$ for a surgical trial, only 67 of these women were aged 70 and older, which limits statistical power. Because the prevalence of POP increases with age, one would have expected more older women in the sample. It could be that the increasing prevalence of comorbidities in older women caused a selection bias by the surgeons, the referring physicians, or the women themselves toward nonsurgical POP treatment. Thus the sample of older women most likely had fewer comorbidities at baseline than the general population of older women with severe POP.

No geriatric-specific evaluations were collected before or after surgery, including functional or cognitive assessment parameters, although one previous study noted that this did not affect outcome when collected preoperatively. ${ }^{23}$ Specifically, it was shown that a preoperative geriatric assessment did not result in differences in physical or mental health outcomes at 6 weeks or 6 months postoperatively as measured using the SF-36 in older women who underwent elective pelvic floor surgery. Patients were also not monitored specifically for postoperative delirium, a highly prevalent postoperative occurrence in older patients. ${ }^{24}$
This study is one of a small number of studies that have examined the effect of age on the surgical treatment of pelvic floor disorders. The cohort of older women had similar outcomes to the younger cohort in terms of pelvic floor symptoms, physical examination parameters, and QOL. The older and younger cohorts had significantly better symptom-specific and general QOL after this surgery, with no significant age differences in the magnitude of this change. The similar outcomes and low complication rates seem to indicate that chronological age should not be an exclusion criterion for an abdominal approach to POP surgery. This is an important study considering the underrepresentation of older persons, and older women in particular, in randomized clinical trials. A review of 20 randomized clinical trials of surgery for stress incontinence ${ }^{3}$ found that the median percentage of subjects aged 70 and older was $3.8 \%$, which is remarkably disproportional to the number of older women undergoing these procedures. As the population ages and increasing numbers of older women are undergoing treatment for $\mathrm{POP}^{25}$ and urinary stress incontinence, ${ }^{26}$ it is imperative that barriers to the inclusion of older women in research on pelvic floor disorders be overcome.

\section{ACKNOWLEDGMENTS}

Financial Disclosure: This research was supported by grants from the National Institute of Child Health and Human Development (U01 HD41249, U10 HD41268, U10 HD41248, U10 HD41250, U10 HD41261, U10 HD41263, U10 HD41269, and U10 HD41267) and the National Institute of Diabetes, Digestive and Kidney Diseases (K24 DK068389). Holly Richter acknowledges grant support and participation in speaker's bureau for Pfizer but no conflict of interest concerning this manuscript. Karl Kreder acknowledges being a Pfizer consultant, participation in speaker's bureau, and grant support; Eli Lilly grant support and speaker's bureau; Astellas grant support and speaker's bureau; Merck equity interests and participation in speaker's bureau; and participation in Boehringer's speaker's bureau but no conflict of interest concerning this manuscript. Patricia Goode, Kimberly Kenton, Morton Brown, Kathryn Burgio, Pamela Moalli, James Wright, and Anne Weber declare they have no conflict of interest to disclose concerning this manuscript.

Author Contributions: Morton B. Brown had full access to all of the data in the study and takes responsibility for the integrity of the data and the accuracy of the data analysis. Holly Richter and Pamela Moalli: study concept and design, acquisition of subjects and/or data, analysis and interpretation of data, preparation of manuscript. Patricia Goode and Kathryn Burgio: study concept and design, interpretation of data, preparation of the manuscript. Kimberly Kenton: study concept and analysis, acquisition of subjects, preparation of the manuscript. Morton Brown: design, data analysis, interpretation of the data. Karl Kreder: acquisition of subjects and/or data, analysis and interpretation of data, preparation of the manuscript. James Wright: acquisition of subjects and/or data, analysis of data, preparation of manuscript. Anne Weber: analysis and interpretation of data, manuscript revision, final approval.

Sponsor's Role: None; investigator-initiated research. 
Pelvic Floor Disorders Network Members

University of Alabama at Birmingham: Holly E. Richter, PhD, MD, Principal Investigator; Kathryn L. Burgio, $\mathrm{PhD}$, Co-Principal Investigator; Patricia S. Goode, MD, MSN, R. Edward Varner, MD, Mark Lockhart, MD, MPH, Co-Investigators; Velria Willis, RN, BSN, Research Coordinator.

Baylor College of Medicine: Paul M. Fine, MD, Principal Investigator; Rodney A. Appell, MD, Co-Principal Investigator; Peter K. Thompson, MD, Peter M. Lotze, MD, Co-Investigators; Naomi Frierson, Research Coordinator.

University of Iowa: Ingrid Nygaard, MD, Principal Investigator; Debra Brandt, RN, Denize Haury, RN, Research Coordinators; Karl Kreder, MD, Catherine S. Bradley, MD, Satish Rao, MD, Co-Investigators.

Johns Hopkins Medical Institutes: Geoffrey Cundiff, MD, Principal Investigator; Victoria Handa, MD, Jamie Wright, MD, Co-Investigators; Mary Elizabeth Sauter, NP, Research Coordinator.

Loyola University, Chicago: Linda Brubaker, MD, Principal Investigator; Mary Pat FitzGerald, MD, Co-Principal Investigator; Kimberly Kenton, MD, Co-Investigator; Dorothea Koch, RN, Charity Ball, RN, Research Coordinators.

University of Michigan: Morton B. Brown, PhD, Principal Investigator; John T. Wei, MD, MS, Co-Principal Investigator; Beverly Marchant, RN, BS, Project Manager; John O.L. DeLancey, MD, Nancy K. Janz, PhD, Dean G. Smith, PhD, Patricia A. Wren, PhD, Co-Investigators; Jim Imus, PhD, Statistician; Yang Wang Casher, MS, Database Programmer.

University of North Carolina at Chapel Hill: Anthony G. Visco, MD, Principal Investigator; AnnaMarie Connolly, MD, John Lavelle, MD, Ellen C. Wells, MD, William Whitehead, PhD, Julia Fielding, MD, Co-Investigators; Mary J. Loomis, RN, Anita K. Murphy, NP, Research Coordinators.

University of Pittsburgh/Magee-Womens Hospitals: Halina Zyczynski, MD, Principal Investigator; Diane Borello-France, PhD, Christiane Hakim, MD, Arnold Wald, MD, Wendy Leng, MD, Pamela A. Moalli, MD, PhD, Co -Investigators; Judy A. Gruss, BS, MS, Research Coordinator.

Robert Park, MD, Steering Committee Chairman.

Anne M. Weber, MD, MS, NICHD Project Scientist.

\section{REFERENCES}

1. Luber KM, Boreo S, Choe JY. The demographics of pelvic floor disorders: Current observations and future projections. Am J Obstet Gynecol 2001; 184:1496-1501.

2. U.S. Census Bureau. Interim Projections by Age, Sex, Race, and Hispanic Origin, 2000-2050 [on-line]. Available at www.census.gov/ipc/www/usinterimproj Accessed June 6, 2006.
3. Morse AN, Labin LC, Young SB et al. Exclusion of elderly women from published randomized trials of stress incontinence surgery. Obstet Gynecol 2004;104:498-501.

4. Bugeja G, Kumar A, Banerjee AK. Exclusion of elderly people from clinical research: A descriptive study of published reports. BMJ 1997;315:1059.

5. Sung VW, Weitzen S, Sokol ER et al. Effect of patient age on increasing morbidity and mortality following urogynecologic surgery. Am J Obstet Gynecol 2006;194:1411-1417.

6. Pugsley H, Barbrook C, Mayne CJ et al. Morbidity of incontinence surgery in women over 70 years old: A retrospective cohort study. BJOG 2005; 112:786-790.

7. Stepp KJ, Barber MD, Yoo E-H et al. Incidence of perioperative complications of urogynecologic surgery in elderly women. Am J Obstet Gynecol 2005;192:1630-1636.

8. Schweitzer KJ, Vierhout ME, Milani AL. Surgery for pelvic organ prolapse in women of 80 years of age and older. Acta Obstet Gynecol Scand 2005;84: 286-289.

9. Brubaker L, Cundiff G, Fine P et al. A randomized trial of colpopexy and urinary reduction efforts (CARE): Design and methods. Control Clin Trials 2003;24:629-642.

10. Brubaker L, Cundiff GW, Fine P et al. Abdominal sacrocolpopexy with Burch colposuspension to reduce urinary stress incontinence. N Engl J Med 2006; 354:1557-1566.

11. Bump RC, Mattiasson A, Bo K et al. The standardization of terminology of female pelvic organ prolapse and pelvic floor dysfunction. Am J Obstet Gynecol 1996;175:10-17.

12. Barber MD, Kuchibhatla MN, Bump RC. Psychometric evaluation of 2 comprehensive condition-specific quality of life instruments for women with pelvic floor disorders. Am J Obstet Gynecol 2001;185:1388-1395.

13. Ware JE, Sherbourne CD. The MOS 36-item short-form health survey (SF-36): I. Conceptual framework and item selection. Med Care 1992;30: 473-483.

14. Ware JE, Kosinski M. SF-36 Physical and Mental Health Summary Scales: A Manual for Users of Version 1. Lincoln, RI: Quality Metric, Inc, 2001.

15. Rogers RG, Coates KW, Kammerer-Donk D et al. A short form of the Pelvic Organ Prolapse/Urinary Incontinence Sexual Function Questionnaire (PISQ12). Int Urogynecol J 2003;14:164-168.

16. Miller MD, Paradis CF, Houck PR et al. Rating chronic medical illness burden in geropsychiatric practice and research. Application of the Cumulative Illness Rating Scale. Psychiatry Res 1992;41:237-248.

17. Lawrence VA, Hazuda HP, Cornell JE et al. Functional independence after major abdominal surgery in the elderly. J Am Coll Surg 2004;149: $762-772$.

18. Williams-Russo P, Sharrock NE, Mattis S et al. Cognitive effects after epidural vs general anesthesia in older adults. JAMA 1995;274:44-50.

19. Nahhas WA, Brown M. Gynecologic surgery in the aged. J Reprod Med 1990;35:550-554.

20. Friedman WH, Gallup DG, Burke JJ et al. Outcomes of octogenarians and nonagenarians in elective major gynecologic surgery. Obstet Gynecol 2006;195:547-553.

21. Carey JM, Leach GE. Transvaginal surgery in the octogenarian using cadaveric fascia for pelvic prolapse and stress incontinence: Minimal one-year results compared to younger patients. Urology 2004;63:665-670.

22. Sultana CJ, Campbell JW, Pisanelli WS et al. Morbidity and mortality of incontinence surgery in elderly women - an analysis of Medicare data. Am J Obstet Gynecol 1997;176:344-348.

23. Richter HE, Redden DT, Duxbury AS et al. Pelvic floor surgery in the older woman: Enhanced compared with usual preoperative assessment. Obstet Gynecol 2005;105:800-807.

24. Marcantonio FR, Flacker JM, Wright JR et al. Reducing delirium after hip fracture: A randomized trial. J Am Geriatr Soc 2001;49:516-522.

25. Boyles SH, Weber AM, Meyn L. Procedures for pelvic organ prolapse in the United States, 1979-97. Am J Obstet Gynecol 2003;188:108-115.

26. Boyles SH, Weber AM, Meyn L. Procedures for urinary incontinence in the United States, 1979-97. Am J Obstet Gynecol 2003;189:70-75. 